\title{
Combination therapy of hTERTR and FAM96A for hepatocellular carcinoma through enhancing apoptosis sensitivity
}

\author{
WAN-PENG WANG and HAI-YING GAO \\ Department of Infectious Diseases, Weifang City People's Hospital, Weifang, Shandong 261041, P.R. China \\ Received May 21, 2016; Accepted April 7, 2017
}

DOI: $10.3892 / \mathrm{etm} .2017 .5505$

\begin{abstract}
Avoidance of apoptosis induced by anticancer drugs is an essential factor of carcinogenesis and a hallmark of resistance to cancer therapy. Human telomerase reverse transcriptase receptor (hTERTR) is a potential anti-cancer agent for inhibiting tumor growth. Family with sequence similarity 96 member A (FAM96A) is a ubiquitous, conserved protein and possesses apoptosome-activating and pro-apoptotic tumor suppressor potential in hepatocellular carcinoma (HCC). In the present study, hTERTR and FAM96A were identified as efficient anti-cancer agents for activating apoptosomes and reducing tumor growth. The potential tumor suppressor function of combination treatment with hTERTR and FAM96A in HCC was also investigated. hTERTR and FAM96A proteins were expressed by genetic engineering and their anti-cancer function was explored in vitro and in vivo. Effects of hTERTR and FAM96A on improvement of apoptotic sensitivity and inhibition of migration and invasion were examined in cancer cells and in a mouse model. The present results demonstrated that the therapeutic effects of hTERTR and FAM96A were effective for inhibiting tumor growth and inducing apoptosis of HCC cells in H22-bearing nude mice compared with single agent treatment. hTERTR and FAM96A were found to bind with apoptotic protease activating factor 1 and human telomerase reverse transcriptase, which enhanced the apoptosis of tumor cells and apoptosis sensitivity. In addition, hTERTR and FAM96A therapy enhanced cytotoxic effects by cytotoxic $\mathrm{T}$ lymphocyte responses, interferon $-\gamma$ release, $\mathrm{T}$ lymphocytes infiltration and apoptosis on tumor cells. Furthermore, hTERTR and FAM96A protein inhibited tumor growth in HCC mice. In conclusion, the present findings suggested that combination therapy with hTERTR and FAM96A may serve as novel tumor suppressor agents.
\end{abstract}

Correspondence to: Professor Hai-Ying Gao, Department of Infectious Diseases, Weifang City People's Hospital, 155 Guangwen Street, Weifang, Shandong 261041, P.R. China

E-mail: haiyinggaoedu@163.com

Key words: human telomerase reverse transcriptase receptor-family with sequence similarity 96 member A, hepatocellular carcinoma, apoptosis, tumor therapy

\section{Introduction}

Hepatocellular carcinoma (HCC) is the most prevalent form of primary liver cancer, which exhibits a high recurrence and the second highest cancer-associated mortality rates following radiotherapy, chemotherapy and surgery in Chinese patients (1). HCC not only exhibits a high incidence among human cancers, but potential therapeutic strategies remain limited, especially for patients with advanced late-stage HCC (2). At present, the recommended clinical therapies of surgery, chemotherapy and radiotherapy present only modest efficacy due to tumor progression and side effects, including myelosuppression and digestive system toxicity during and following the treatment period (3-5). Therefore, novel clinical strategies are required in order to enhance curative effects, minimize adverse response and potentially prolong survival of patients with HCC $(6,7)$.

Various oncolytic protocols for targeting different signal pathways have been characterized $(8,9)$. These cellular signal pathways presented key signal transduction for various extracellular growth factors and receptors of HCC cells. However, the high occurrence $(62-82 \%)$ of drug resistance is a major issue in clinical HCC therapy $(10,11)$. Tumors have been demonstrated to acquire apoptotic-resistance during early stage apoptosis or incomplete apoptotic responses to oncolytic treatments and anticancer drugs, and the consequent requirement for long-term medical therapy presented a major clinical problem in HCC (12). Therefore, novel effective therapeutic agents for HCC therapy are required to inhibit metastasis for patients with HCC.

Human telomerase reverse transcriptase (hTERT) is a target of tumor therapy which is strongly expressed in the majority of tumor cells and is rarely expressed in normal cells (13). A previous study has reported that hTERT is overexpressed in $80 \%$ HCC cells, and suggest that telomere elongation is a potential target of gene therapy for HCC (14). In the present study, it was demonstrated that the anti-tumor efficacy of hTERT receptor (hTERTR) was mediated by altering endogenous telomerase activity; thereby significantly inhibiting HCC growth in vitro and strongly suppressing tumor cell proliferation and cancer cell metastasis in anti-telomerase therapy mice.

Family with sequence similarity 96 member A (FAM96A) is identified as a member of the cytosolic $\mathrm{Fe} / \mathrm{S}$ protein in charge of regulator of cellular iron homeostasis and assembly machinery, which exhibits apoptosome-activating activities 
and pro-apoptotic tumor suppressor potential in HCC (15-17). The results of the present study demonstrated that FAM96A induced no adverse side effects for normal, non-cancerous human cells, which indicated that FAM96A protein may be able to enhance apoptosis sensitivity via the mitochondrial apoptosis pathway in vitro and promote immunologic cytotoxicity for apoptotic fragments in vivo (18).

In the present study, combination therapy of hTERTR and FAM96A for HCC through apoptosis was explored and their antitumor efficacies were confirmed in a murine model of HCC. Notably, compared with sole administration of FAM96A and hTERTR, combination therapy demonstrated markedly improved therapeutic effects for HCC in vitro and in vivo. These findings support the use of multi-target fusion protein drugs for treatment of HCC cells and suggest that hTERTR and FAM96A may be efficient anti-cancer agents for HCC treatment.

\section{Materials and methods}

Ethical approval. The present study was performed in strict accordance with the recommendations in the Guide for the Care and Use of Laboratory Animals (19) of Weifang City People's Hospital. All experimental protocols and animal maintenance were approved by the Committee on the Ethics of Weifang City People's Hospital (Shandong, China). All surgery and euthanasia were performed to minimize suffering.

Cells culture and reagents. HepG2 and $\mathrm{H} 22$ cells were obtained from Frederick Cancer Research Facility, Division of Cancer Treatment Tumor Repository (Frederick, MD, USA) and normal mice liver cells (NCTC-1496 cells) were obtained from American Type Culture Collection (Manassas, VA, USA). All cells were cultured in Dulbecco's modified Eagle's medium (DMEM) supplemented with $10 \%$ heat-inactivated fetal bovine serum, $3 \mathrm{mM}$ L-glutamine, $50 \mu \mathrm{g} / \mathrm{ml}$ gentamicin (all from Biowhittaker; Lonza Group, Ltd., Basel, Switzerland) and $1 \%$ penicillin/streptomycin under standard culture conditions $\left(5 \% \mathrm{CO}_{2}, 37^{\circ} \mathrm{C}\right)$. Cells were treated with $0.10,0.18,0.25$, $0.32 \mathrm{mg} / \mathrm{ml} \mathrm{hTERTR}$ and/or FAM96A for $72 \mathrm{~h}$ at $37^{\circ} \mathrm{C}$.

Construction of recombinant hTERTR and FAM96A. The hTERTR and FAM96A genes were obtained from lung tissue from the Microbiological Laboratory of Shandong University (Shandong, China). A pET-27b expression system (cat. no. addgene 0020; Shanghai North Connaught Biological Technology Co., Ltd, Shanghai, China) was used to construct the recombinant hTERTR and FAM96A proteins. DNA sequence encoding 130 bp of FAM96A (forward, 5'-ATGTTA TCGTTCTTCCGCAAG-3' and reverse, 5'-CCAGCTGAG AGAGGGATGGC-3') was amplified by polymerase chain reaction (PCR) from pMD-18-FAM96A (Weifang Medical University, Weifang, China) using $1 \mu \mathrm{l}$ PCR clone product mixed with $10 \mu$ l of TaqMan Universal PCR MasterMix (Applied Biosystems; Thermo Fisher Scientific, Inc., Waltham, MA, USA).PCR was performed under the following conditions: $95^{\circ} \mathrm{C}$ for $30 \mathrm{sec}, 30$ cycles at $95^{\circ} \mathrm{C}$ for $15 \mathrm{sec}$ and $55^{\circ} \mathrm{C}$ for $1 \mathrm{~min}$ and then $72^{\circ} \mathrm{C}$ for $1 \mathrm{~min}$. FAM96A (50 ng) was subcloned into the rPET-27b plasmids and named rPET-27-FAM96A using electrotransformation (cat. no. 1359; Bio-Rad Laboratories,
Inc., Hercules, CA, USA) following a previously described protocol (20). Gene edited cell-penetrating peptide (CPP; Weifang Medical University) was inserted into plasmids with proteins following $25-\mu \mathrm{l}$ volume PCR to induce cells to take the plasmids up. The same method was used to clone recombinant hTERTR (forward, 5'-AAGGAATTTGTAACAAAGGT-3' and reverse, 5'-AGACCTGTGAGATGACCTCC-3') with the CPP into PET-27b plasmids, which were then named rPET-27-hTERTR. PCR, as performed previously and gene sequencing (Invitrogen; Thermo Fisher Scientific, Inc.) were used to select the correct monoclonal sequence identified by Invitrogen (Invitrogen; Thermo Fisher Scientific, Inc.) (21). Recombinant rPET-27-hTERTR $(4 \mu \mathrm{g})$ or rPET-27-FAM96A $(4 \mu \mathrm{g})$ was expressed in E. coli in LB medium at $37^{\circ} \mathrm{C}$ for $12 \mathrm{~h}$. hTERTR and FAM96A protein was extracted and purified as described previously (17).

Western blotting. The purified hTERTR or FAM96A was homogenized and separated by SDS-PAGE, and subsequently transferred to nitrocellulose membranes. For western blot analysis, hTERT and apoptotic protease activating factor 1 (APAF1) were prepared. The detection of protein was carried out by incubating the membranes with hTERT and APAF1 with IL-1 as a negative control. The procedures were performed as previously described (17). All experiments were performed in triplicate and repeated at least three times.

Animal experiments. A total of 80 specific pathogen-free female BALB/c nude mice (age, 6-week old; weight, 30-35 g) were purchased from Harbin Veterinary Research Institute (Harbin, China). Mice were feed under pathogen-free conditions and maintained at a controlled environment (temperature, $23 \pm 1^{\circ} \mathrm{C}$; humidity, 50-60\%) with an artificial simulation of $12 \mathrm{~h}$ light/dark cycles. H22 cells $\left(1 \times 10^{5}\right)$ in $200 \mu \mathrm{l}$ PBS were injected into the right flank of female BALB/c nude mice to establish HCC. Therapy for tumor-bearing mice with hTERTR and/or FAM96A, or PBS was initiated when tumor diameters reached 6-8 $\mathrm{mm}$ at 7 days in the HCC mouse model following tumor inoculation. Mice with HCC were randomly divided into 4 groups $(\mathrm{n}=20$ each) and injected intratumorally with $0.25 \mathrm{mg}$ hTERTR and/or $0.32 \mathrm{mg}$ FAM96A in PBS buffer $(200 \mu \mathrm{l})$, or the same volume of PBS $(200 \mu 1)$, respectively. Each treatment was subsequently administered a further 7 times at two-day intervals, giving a total of 15 administrations. Tumor diameters were recorded once every two days and tumor volume was calculated using the following formula: $0.52 \mathrm{x}$ smallest diameter ${ }^{2} \mathrm{x}$ largest diameter.

Lactate dehydrogenase $(\mathrm{LDH})$ and interferon $($ IFN)- $\gamma$ release assays. HepG2 $\left(1 \times 10^{6}\right), \mathrm{H} 22\left(1 \times 10^{6}\right)$ and NCTC-1496 cells $\left(1 \times 10^{6}\right)$ were incubated with hTERTR $(0.20 \mu \mathrm{g} / \mathrm{ml})$ and/or FAM96A $(0.20 \mu \mathrm{g} / \mathrm{ml})$ in DMEM for $96 \mathrm{~h}$ at $37^{\circ} \mathrm{C}$. Cells were washed with PBS three times for $2 \mathrm{~min}$ at room temperature. Cells were subsequently incubated with $1 \%$ Triton-X-100 at $37^{\circ} \mathrm{C}$ for $30 \mathrm{~min}$. LDH assay was determined using the CytoTox 96 assay kit (Promega Corporation, Madison, WI, USA) and recorded at $490 \mathrm{~nm}$ according to manufacturer's protocol. For IFN- $\gamma$ release assays, splenocytes were harvested from euthanized animals. Splenocytes $\left(1 \times 10^{6}\right)$ were subsequently incubated with $\mathrm{UV}$-inactivated $\mathrm{H} 22$ cells $\left(1 \times 10^{8}\right)$ in DMEM at 
$37^{\circ} \mathrm{C}$ for $72 \mathrm{~h}$. Cells were centrifuged at $8,000 \mathrm{xg}$ for $10 \mathrm{~min}$ at $37^{\circ} \mathrm{C}$ and IFN- $\gamma$ release in supernatants of the DMEM medium was subsequently measured by ELISA (cat. no. DY485; Bio-Rad Laboratories, Inc.) according to manufacturer's protocol. Then, T cells $\left(1 \times 10^{6}\right)$ from the splenocyte sample were purified, as described previously (22), and co-cultured with fresh $\mathrm{H} 22$ cells for $4 \mathrm{~h}$ at $37^{\circ} \mathrm{C}$ with target ratios of 5:1, 15:1 and 40:1. Specific cytotoxic T lymphocyte (CTL) response to the target cells was determined using a Pierce ${ }^{\mathrm{TM}}$ LDH Cytotoxicity assay kit (cat. no. 88953; Thermo Fisher Scientific, Inc.) cytotoxicity assays as described previously (23).

Reverse transcription-quantitative polymerase chain reaction (RT-qPCR). Total cellular RNA was extracted from $\mathrm{H} 22$ cells with an RNeasy Mini kit (Qiagen Sciences, Inc., Gaithersburg, MD, USA) and $1 \mu \mathrm{g}$ RNA was subjected to a cDNA synthesis kit (Bio-Rad Laboratories, Inc.). A total of $10 \%$ of the cDNA sample was subjected to a $25-\mu 1$ PCR (cDNA, $10 \mathrm{ng}, 5 \mu \mathrm{l}$, PCR buffer, $2 \mu 1$, DNA polymerase, $0.5 \mu 1$, primers, $2 \mu \mathrm{l}$, water, $15.5 \mu \mathrm{l}$ ) carried out in an iCycler thermal cycler (Bio-Rad Laboratories, Inc.) using iQ SYBR-Green Supermix (Bio-Rad Laboratories, Inc.). The reaction conditions were performed as follows: $95^{\circ} \mathrm{C}$ for $10 \mathrm{~min}, 35$ cycles of $95^{\circ} \mathrm{C}$ for $20 \mathrm{sec}$ and $58^{\circ} \mathrm{C}$ for $1 \mathrm{~min}$. The forward and reverse primers for B-cell lymphoma 2 (Bcl-2) and c-Myc were synthesized by Invitrogen (Thermo Fisher Scientific, Inc.). Primers were as follows: Bcl-2 forward, 5'-CTGGTGGACAACATCGCTCTG-3' and reverse, 5'-GGTCTGACCTCACTTGTG-3'; c-Myc forward, 5'-TTC ATCCAGGATCGAGCAGA-3' and reverse, 5'-GCAAAG TAGAAGGCAACG-3'; GAPDH forward, 5'-GGCCAAGAT CATCCATGACAACT-3' and reverse, 5'-ACCAGGACATGA GCTTGACAAAGT-3'. The amplified PCR products were quantified by measuring the calculated quantification cycles (Cq) of sample and GAPDH mRNA. Relative changes in mRNA expression were calculated by the $2^{-\Delta \Delta \mathrm{Cq}}$ method (24). The results are expressed as the $n$-fold difference relative to GAPDH (relative expression levels).

Tumor cell migration and invasion assays. HepG2 cells were treated with hTERTR and/or FAM96A and non-treated cells were used as control. For migration assay, HepG2 cells $\left(1 \times 10^{5}\right)$ were incubated with hTERTR $(0.20 \mu \mathrm{g} / \mathrm{ml})$ and/or FAM96A $(0.20 \mu \mathrm{g} / \mathrm{ml})$ in DMEM for $96 \mathrm{~h}$ at $37^{\circ} \mathrm{C}$ using control culture inserts (BD Biosciences, Franklin Lakes, NJ, USA). For invasion assay, hTERTR and/or FAM96A-treated cells were suspended at a density of $1 \times 10^{5}$ cells in $500 \mu 1$ serum-free DMEM. HepG2 cells were then placed in the upper chambers of BD BioCoat Matrigel Invasion Chambers (BD Biosciences) for $96 \mathrm{~h}$ at $37^{\circ} \mathrm{C}$ according to the manufacturer's instructions. $0.1 \%$ crystal violet was used to stain the membrane for 30 min at $37^{\circ} \mathrm{C}$. After washing with PBS, tumor cell invasion and migration were counted in at least three random stained fields of view via microscopy (Olympus BX51; Olympus Corporation, Tokyo, Japan).

Flow cytometry. HepG2 and H22 cells were cultured in DMEM medium supplied 10\% fetal calf serum. HepG2 and H22 $\left(1 \times 10^{6}\right)$ cells were incubated with PBS, hTERTR and/or FAM96A at $37^{\circ} \mathrm{C}$ for $72 \mathrm{~h}$. Subsequently, apoptosis of suspended cells were analyzed by flow cytometry. Cells were collected and suspended with Annexin V-FITC and PI for $30 \mathrm{~min}$ at $4^{\circ} \mathrm{C}$ according to the manufacturer protocol. Fluorescence was measured with a fluorescence-activated cell sorting flow cytometer (FCS Express ${ }^{\mathrm{TM}} 4$ IVD; BD Biosciences) and analyzed using Quantity One software (version 3.0; Bio-Rad Laboratories, Inc.).

Immunohistochemical staining. Tumor tissues were fixed using $10 \%$ formalin solution for $12 \mathrm{~h}$ at $4^{\circ} \mathrm{C}$. Immunohistochemical staining was performed using an avidin-biotin-peroxidase technique on tumor tissues obtained from the BALB/c mice on day 30. Paraffin-embedded tissue sections $4 \mu \mathrm{m}$ thick were prepared and epitope retrieval was performed for further analysis. The paraffin sections were incubated with hydrogen peroxide (3\%) for $10-15 \mathrm{~min}$ at $37^{\circ} \mathrm{C}$ and were subsequently blocked with a regular blocking solution $(5 \%$ skim milk powder) for $10 \sim 15$ minutes at $37^{\circ} \mathrm{C}$. Sections were incubated with anti-Annexin antibody (1:2,000, cat. no. ab14196; Abcam, Cambridge, UK) at $4^{\circ} \mathrm{C}$ for $12 \mathrm{~h}$ following blocking. All sections were washed three times with $\mathrm{PBS}$ at $37^{\circ} \mathrm{C}$ for $5 \mathrm{~min}$ and incubated with horseradish peroxidase (HRP)-conjugated goat anti-rabbit IgG mAb (Bio-Rad Laboratories, Inc., Hercules, CA, USA) for $1 \mathrm{~h}$ at $37^{\circ} \mathrm{C}$ and were counterstained with hematoxylin or DAPI for $1 \mathrm{~h}$ at $37^{\circ} \mathrm{C}$. Images were captured with a ZEISS LSM 510 confocal microscope (Zeiss AG, Oberkochen, Germany ) at $488 \mathrm{~nm}$.

Statistical analysis. All data are presented as the mean \pm standard error of the mean. Comparisons of data between multiple groups were performed using one-way analysis of variance followed by a Tukey's multiple comparison post hoc test. $\mathrm{P}<0.05$ was considered to indicate a statistically significant difference.

\section{Results}

Construction of recombinant hTERTR and FAM96A, and in vitro activity. In order to construct the recombinant protein, two recombinant plasmids were structured, rPET-27b-hTERTR and rPET-27b-FAM96A. The structure of rPET-27b-hTERTR and rPET-27b-FAM96A are presented in Fig. 1A. The recombinant plasmids of rPET-27b-hTERTR and rPET-27b-FAM96A were respectively expressed by E. coli. The molecular weight of hTERTR was $\sim 28 \mathrm{kDa}$ and FAM96A was $\sim 30 \mathrm{kDa}$ (Fig. 1B). Western blotting revealed a band of $\sim 27 \mathrm{kDa}$ (hTERTR) and $30 \mathrm{kDa}$ (FAM96A) and identified the purified protein of hTERTR or FAM96A specifically bound to hTERT and APAF1, respectively (Fig. 1C). ELISA also revealed that hTERTR-FAM96A was able to cross-bind both hTERT and APAF1 (Fig. 1D). These results indicated that the recombinant proteins hTERTR and FAM96A were purified successfully and possessed the expected binding potentials.

Cytolytic effects of hTERTR and/or FAM96A on normal cells and HCC cells. In the present study, the cytolytic effects of hTERTR and/or FAM96A on H22 and HepG2 tumor cells were investigated to determine the cytotoxic effects of hTERTR and/or FAM96A via LDH assay, using untreated cells as a control. Different dosages of hTERTR and/or FAM96A (0.10, $0.18,0.25,0.32 \mathrm{mg} / \mathrm{ml}$ ) induced different cytotoxic effects on 


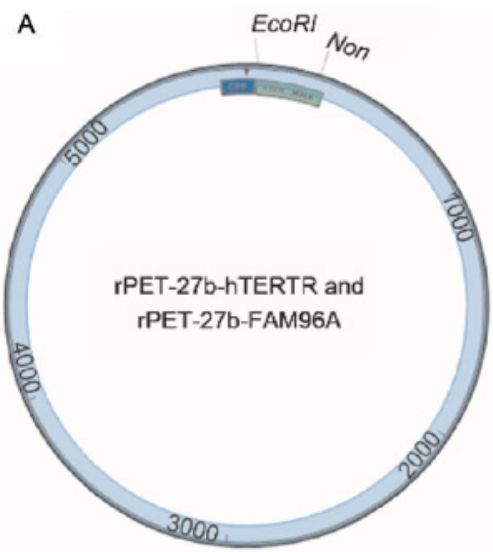

C

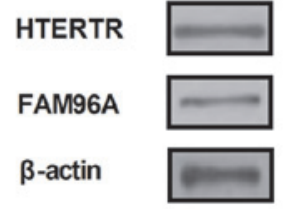

B

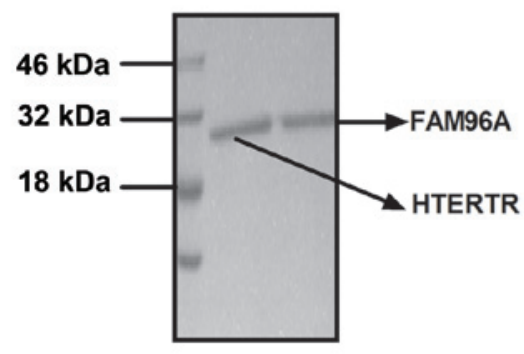

D

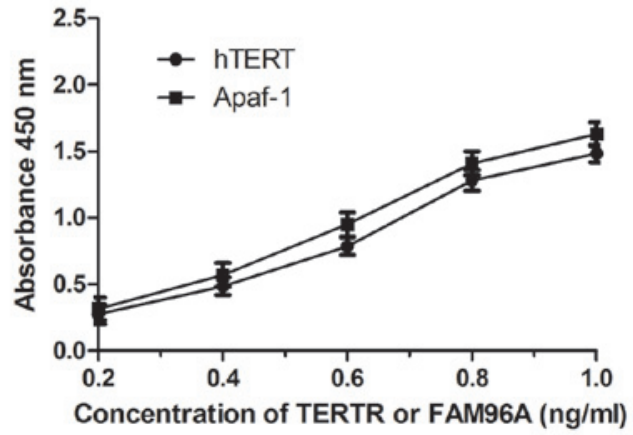

Figure 1. Construction of recombinant plasmids and in vitro activities of hTERTR and FAM96A. (A) Simplified structure of the recombinant plasmids of rPET-27b-hTERTR and rPET-27b-FAM96A. (B) SDS-PAGE analysis of purified hTERTR and FAM96A under reducing conditions. (C) Specificity of hTERTR or FAM96A was analyzed by western blotting. (D) Specific interaction of hTERTR and FAM96A with hTERT and APAF1, respectively. hTERTR, human telomerase reverse transcriptase receptor; FAM96A, family with sequence similarity 96 member A; hTERT, human telomerase reverse transcriptase; APAF1, apoptotic protease activating factor 1 .

tumor cell lines in a time-dependent manner, but were not toxic for normal hepatocytes (Fig. 2A-D). The different dosages of hTERTR or FAM96A $(0.10-0.32 \mathrm{mg} / \mathrm{ml})$ also demonstrated inhibiting effects for tumor cell growth in a dose-dependent manner at $72 \mathrm{~h}$ post-treatment. The present results indicated that hTERTR $(0.18 \mathrm{mg} / \mathrm{ml})$ and FAM96A $(0.25 \mathrm{mg} / \mathrm{ml})$ was enough to inhibit growth of hepatic tumor cells. Nevertheless, combination treatment with hTERTR and FAM96A resulted in great inhibition compared with either agent administered alone. It was observed that there was no significant difference in the growth-inhibiting rate at the maximum concentration levels between hTERTR and FAM96A at $72 \mathrm{~h}$ post-treatment. These data suggested that combination treatment of hTERTR and FAM96A significantly inhibited HCC cells.

Improvement of apoptotic sensitivity in hTERTR and/or FAM96A-treated HCC cells. The cytotoxic effects on human or mouse normal liver cell lines at the highest dose of hTERTR $(0.18 \mathrm{mg} / \mathrm{ml})$ or FAM96A $(0.25 \mathrm{mg} / \mathrm{ml})$ were also investigated. The present results indicated that hTERTR $(0.18 \mathrm{mg} / \mathrm{ml})$, FAM96A $(0.25 \mathrm{mg} / \mathrm{ml})$ or combination treatment [hTERTR $(0.18 \mathrm{mg} / \mathrm{ml})$ and FAM96A $(0.25 \mathrm{mg} / \mathrm{ml})]$ had no significant cytotoxic effect on NCTC-1496 cells (Fig. 3A). In addition, treatment with hTERTR and/or FAM96A induced apoptosis of tumor cells (Fig. 3B). Furthermore, the inhibitory effects of hTERTR and/or FAM96A on migration and invasion in HCC cells were investigated. The present results indicated that hTERTR and/or FAM96A administration significantly inhibited migration (Fig. 3C) and invasion (Fig. 3D) of HCC cells.
Notably, these findings suggest that combination treatment with hTERTR and FAM96A markedly promoted apoptosis and inhibited migration and invasion of hepatocellular tumor cells. These results suggested that hTERTR and/or FAM96A significantly inhibited hepatocellular tumor cells growth, migration and invasion.

Therapeutic effects of hTERTR-FAM96A in HCC tumor-bearing mice. Therapeutic effects of hTERTR and/or FAM96A in HCC tumor-bearing mice were evaluated by measuring tumor volume. Also, tumor cellular immunity was analyzed at 10 days following treatment. The results in Fig. 4A showed that treatment with hTERTR and FAM96A exhibited significantly increased inhibitory effects for HCC tumor growth compared with hTERTR, FAM96A and PBS groups in a 30-day observation. The result in Fig. 4B showed that treatment with hTERTR and FAM96A markedly suppressed expressions of apoptosis-suppressing genes (Bcl-2 and C-myc) in tumors compared with hTERTR or FAM96A-treated tumors. In addition, the results in Fig. 4C showed that apoptosis rate was increased on tumor surface following combination treatment with hTERTR and FAM96A. In addition, CTL responses and IFN- $\gamma$ release were also assessed in H22-bearing mice. Treatment with hTERTR and FAM96A resulted in significantly higher CTL activity and IFN- $\gamma$ release when compared with control groups (Fig. 4D and E). Furthermore, the date in Fig. 4F indicated that hTERTR and FAM96A-treated tumors generated more apoptotic bodies analyzed by immunofluorescence compared with 
A

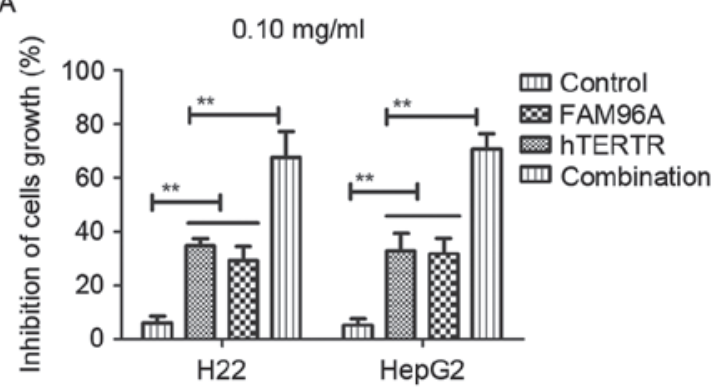

C

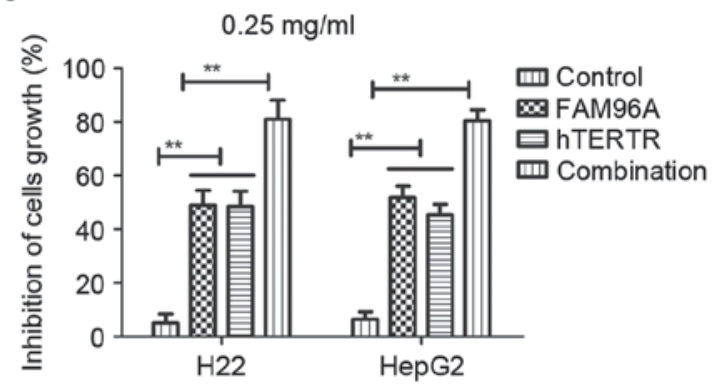

B

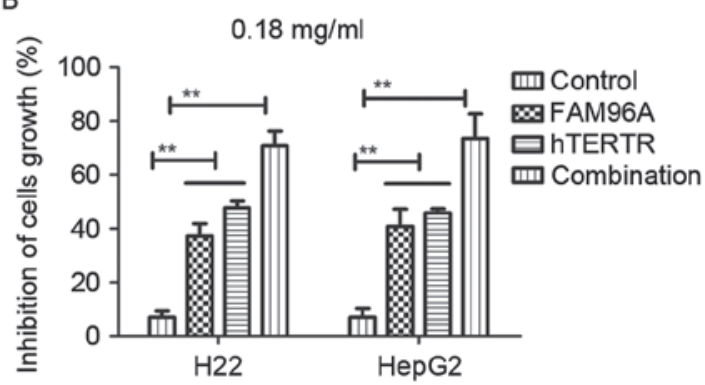

D

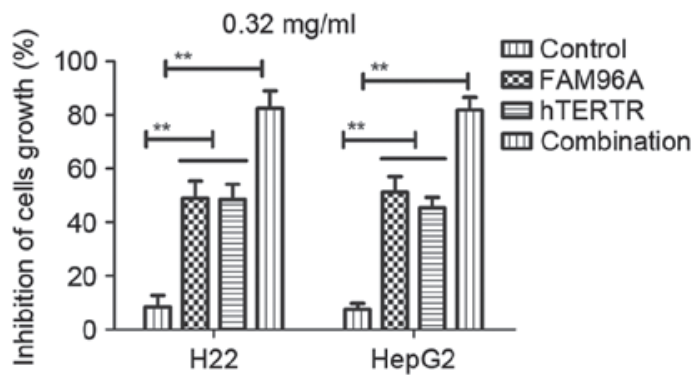

Figure 2. HCC tumor cell growth was inhibited by hTERTR, FAM96A or combination treatment. (A) hTERTR, FAM96A or combination treatment inhibited HCC cell growth at dosages of (A) 0.10 , (B) 0.18 , (C) 0.25 and (D) $0.32 \mathrm{mg} / \mathrm{ml}$ for $72 \mathrm{~h}$. Data are presented as the mean \pm standard error of the mean of triplicate samples. ${ }^{* *} \mathrm{P}<0.01$. HCC, hepatocellular carcinoma; hTERTR, human telomerase reverse transcriptase receptor; FAM96A, family with sequence similarity 96 member A.

A

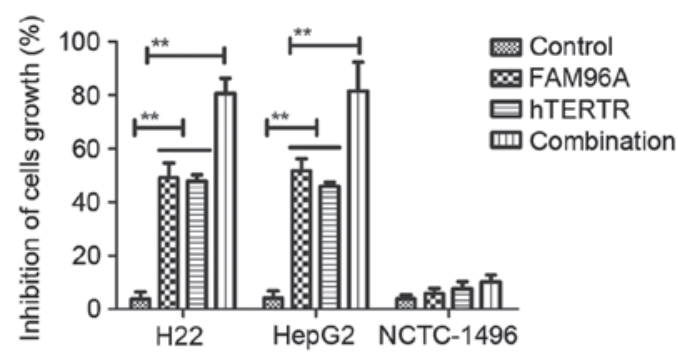

C

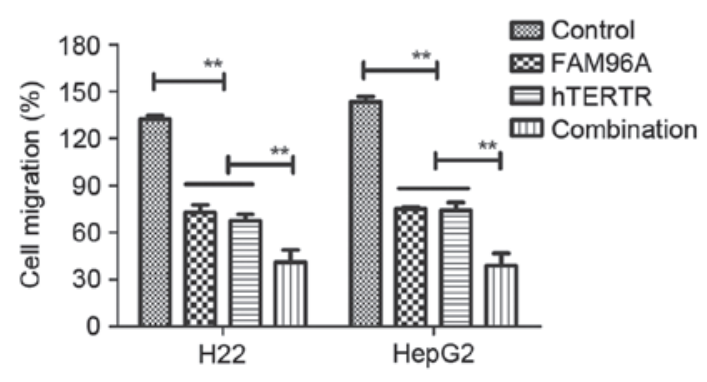

B

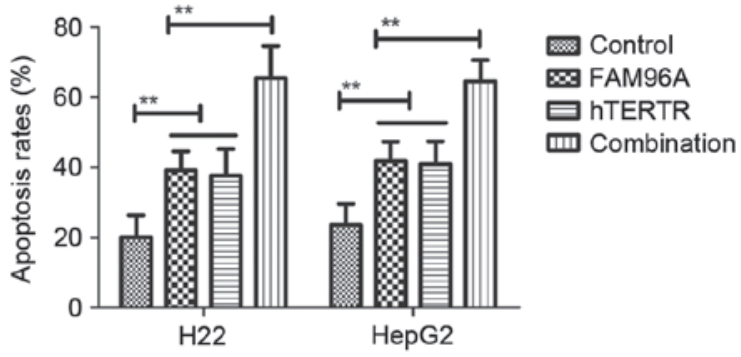

D

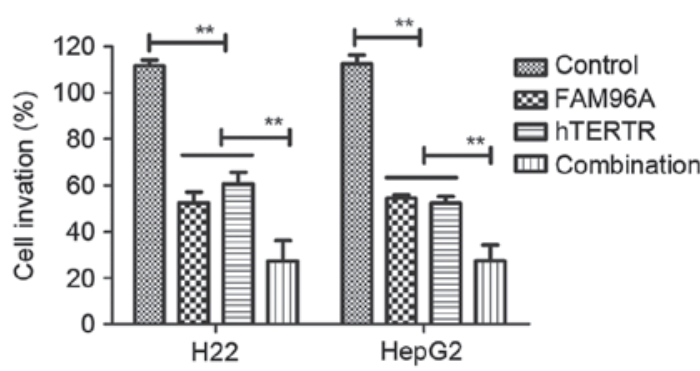

Figure 3. Inhibition of the biological activities of HCC cells at the maximum dose toxicity of hTERTR and/or FAM96A. (A) Treatment with hTERTR and/or FAM96A significantly inhibited HCC cells growth, whereas no significant effect was observed in normal liver cell growth. (B) Treatment with hTERTR and/or FAM96A significantly enhanced HCC cell apoptosis-sensitivity induced by cisplatin. (C) Treatment with hTERTR and/or FAM96A significantly suppressed HCC cell migration in vitro. (D) Invasion of hepatic carcinoma cells was significantly suppressed following treatment with hTERTR and/or FAM96A. Data are presented as the mean \pm standard error or the mean of triplicate samples. ${ }^{* *} \mathrm{P}<0.01$. HCC, hepatocellular carcinoma; hTERTR, human telomerase reverse transcriptase receptor; FAM96A, family with sequence similarity 96 member A.

single agent-treated tumors. These data suggest that hTERTR and FAM96A improved apoptosis of HCC cells and enhanced CTL responses, more apoptotic bodies and lymphocytes for HCC tumors.

\section{Discussion}

The majority of patients with HCC have exhibited drug resistance and reduced apoptosis-induced immunologic 


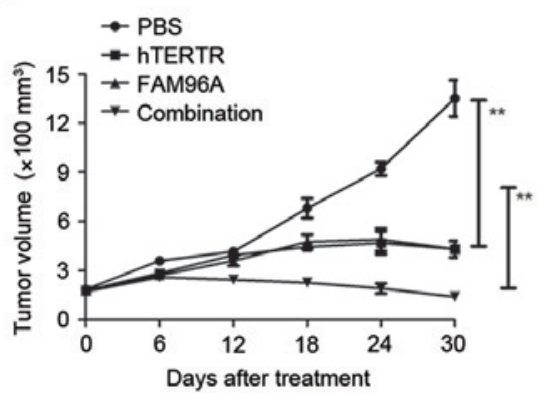

D

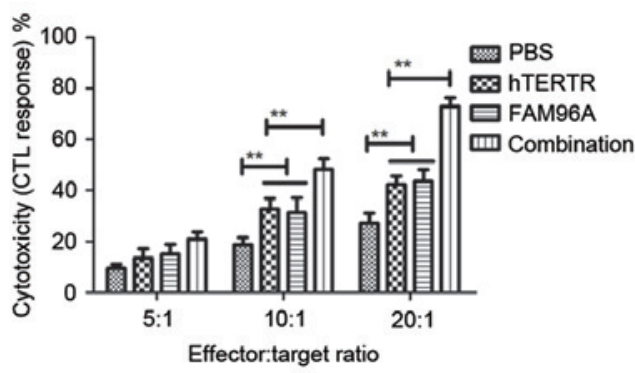

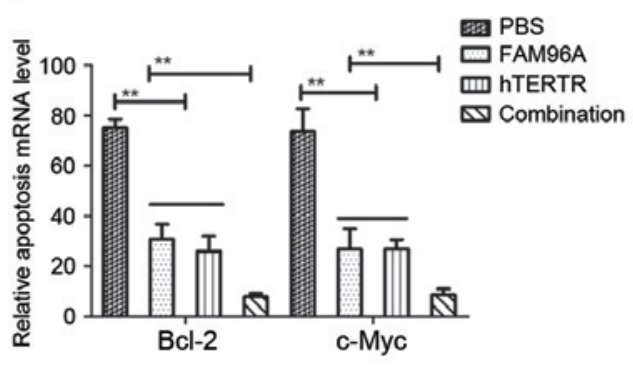

E
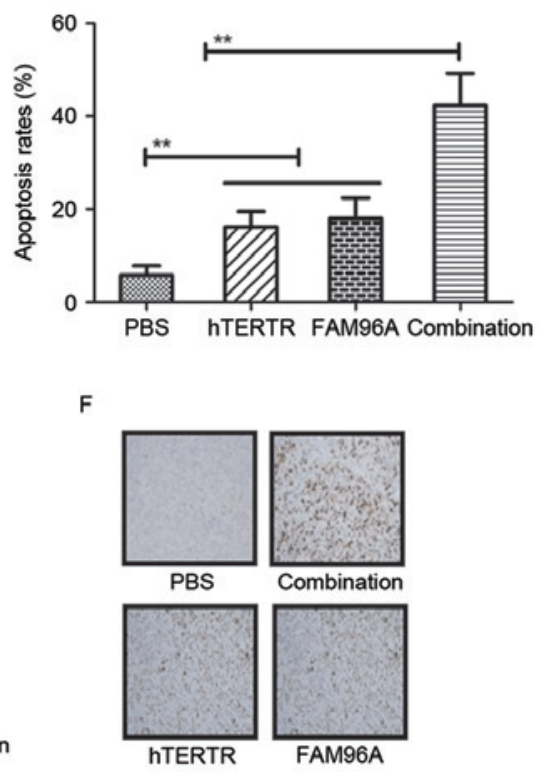

Figure 4. Treatment with hTERTR and/or FAM96A suppressed tumor growth and enhanced tumor apoptosis potency. (A) Mean value of tumor volume in each experimental group in HCC model. (B) mRNA analysis of hTERTR and/or FAM96A-induced apoptosis in tumor cells. (C) Apoptosis rate of H22 cells were analyzed by flow cytometry. (D) CTL response of H22 cells was analyzed by lactate dehydrogenase assay. (E) Tumor-specific IFN- $\gamma$ released from stimulated splenocytes in HCC cells was analyzed by ELISA. (F) Apoptotic bodies were analyzed by immunofluorescence in each experimental group. Data are presented as the mean \pm standard error of the mean of triplicate samples. ${ }^{* *} \mathrm{P}<0.01$. HCC, hepatocellular carcinoma; hTERTR, human telomerase reverse transcriptase receptor; FAM96A, family with sequence similarity 96 member A; CTL, cytotoxic T lymphocyte; IFN, interferon; BCL, B-cell lymphoma.

cytotoxicity in clinical trials (25). The ability to escape apoptosis induced by immunologic cytotoxicity is a distinguishing feature of tumorigenesis and an important factor in resistance to anti-cancer treatments $(26,27)$. A recent study has indicated that HCC cells that developed resistance to the telomerase-activated prodrug acycloguanosyl 5'-thymidyltriphosphate may undergo spontaneous apoptosis (28). In addition, a previous report demonstrated that dominant negative p63- $\alpha$ induced drug resistance in $\mathrm{HCC}$ by interference with apoptosis signaling pathways (29). Furthermore, down-regulation of aquaporin expression has been demonstrated to induce an increasing resistance to apoptosis in HCC (30). These findings suggested that resistance to apoptosis was a major obstacle in clinical treatment of HCC. Therefore, it was hypothesized that inhibition of resistance to apoptosis may enhance the therapeutic efficacy for patients with HCC.

In previous studies, the therapeutic effects of targeting hTERT in patients with HCC were reported $(31,32)$. The hTERT protein is identified as a component of the cytosolic Fe/S protein assembly machinery, and it is evolutionarily conserved and critical for cellular iron homeostasis (33). In the present study, hTERTR was identified as a novel target-regulating protein by binding with hTERT in human and mouse hepatic carcinoma cells. Apoptosis of tumor cells was also examined to confirm their association with hTERTR; however, administration of a single anticancer agent of hTERTR was not able to achieve the desired therapeutic effects in HCC tumor model.

FAM96A is a $21 \mathrm{kDa}$ (including the cell-penetrating peptide) protein that is expressed at low levels in tumor cells (34). Stehling et al (15) previously demonstrated that FAM96A is associated with metabolism, DNA maintenance, protein translation and facilitating the effective induction of cell death via the mitochondrial apoptosis pathway by binding to pro-apoptotic APAF1 protein; however, it is poorly expressed in most tumor cells. FAM96A, as a pro-apoptotic tumor suppressor, presented potential therapeutic effects for tumor cells (15). Previous studies reported that reestablishment of FAM96A expression enhanced apoptosis sensitivity and inhibited tumor growth, leading to the hypothesis that the limited apoptosis sensitivity of cancer cells was associated with FAM96A loss $(16,18)$. In the present study, it was observed that FAM96A with cell penetrating peptide efficiently inhibited tumor cells growth and induced apoptosis. However, in the HCC mouse model, tumor cell were not eliminated completely.

Several challenges remain in reducing HCC-associated resistance to apoptosis by targeted anti-cancer treatments (35-37). Combinations of anti-cancer agents have previously demonstrated a strong therapeutic effect (38-40). Therefore, combination treatment of hTERTR and FAM96A was investigated in HCC cells and a xenograft mouse model. The present study indicated that combination treatment with hTERTR and FAM96A was efficient for HCC inhibition, which elucidated a reference for protein drugs for HCC therapy $(41,42)$. In addition, combination treatment with hTERTR and FAM96A presented a better outcome by inducing tumor cell apoptosis compared with single hTERTR or FAM96A treatments in murine HCC models. Furthermore, the efficacy of combination treatment hTERTR and FAM96A also generated tumor-specific CTL responses, which indicated that an increase in apoptotic bodies and debris was considered as potential cytotoxic toxicity mediated by cellular immunity. 
In conclusion, combination treatment hTERTR and FAM96A was identified as a hTERT-targeting and FAM96Areestablishing molecular therapy, which has the potential to inhibit hepatic carcinoma tumor cells growth by prompting apoptosis, which suggest the beneficial effects of targeted therapy.

\section{References}

1. Fung SK and Lok AS: Management of patients with hepatitis B virus-induced cirrhosis. J Hepatol 42 (Suppl): S54-S64, 2005.

2. Huang YH, Wu JC, Chen SC, Chen CH, Chiang JH, Huo TI, Lee PC, Chang FY and Lee SD: Survival benefit of transcatheter arterial chemoembolization in patients with hepatocellular carcinoma larger than $10 \mathrm{~cm}$ in diameter. Aliment Pharmacol Ther 23 $129-135,2006$

3. Devlin EJ, Denson LA and Whitford HS: Cancer treatment side effects: A Meta-analysis of the relationship between response expectancies and experience. J Pain Symptom Manage 54: 245-258.e2, 2017.

4. Kudo K and Nakagawa K: Management of side effects with platinum doublet chemotherapy used for treatment of non-small cell lung cancer. Nihon Rinsho 73 (Suppl 2): S542-S547, 2015 (In Japanese).

5. Vincent J, de Boer M, Lobbezoo DJ, Smeets RE and Tjan-Heijnen VC: Combination of exemestane and everolimus may produce toxic side effects: A new treatment option for metastatic hormone-sensitive breast cancer. Ned Tijdschr Geneeskd 158: A7523, 2014 (In Dutch).

6. Lubienski A, Bitsch RG, Schemmer P, Grenacher L, Düx M and Kauffmann GW: Long-term results of interventional treatment of large unresectable hepatocellular carcinoma (HCC): Significant survival benefit from combined transcatheter arterial chemoembolization (TACE) and percutaneous ethanol injection (PEI) compared to TACE monotherapy. Rofo 176: 1794-1802, 2004.

7. Yeh ML, Huang CI, Huang CF, Hsieh MY, Huang JF, Dai CY, Lin ZY, Chen SC, Yu ML and Chuang WL: Neoadjuvant transcatheter arterial chemoembolization does not provide survival benefit compared to curative therapy alone in single hepatocellular carcinoma. Kaohsiung J Med Sci 31: 77-82, 2015.

8. Guo Z, Yu H, Liu C, Si T, Yang X, Zhang W, Xu Y and Li Y: Advances in endovascular therapy to treat primary hepatocellular carcinoma. Drug Discov Ther 9: 342-351, 2015.

9. Jiang J, Yu C, Chen M, Tian S and Sun C: Over-expression of TRIM37 promotes cell migration and metastasis in hepatocellular carcinoma by activating Wnt $/ \beta$-catenin signaling. Biochem Biophys Res Commun 464: 1120-1127, 2015.

10. Mizukoshi E, Nakagawa H, Kitahara M, Yamashita T, Arai K, Sunagozaka H, Iida N, Fushimi K and Kaneko S: Phase I tria of multidrug resistance-associated protein 3-derived peptide in patients with hepatocellular carcinoma. Cancer Lett 369: 242-249, 2015

11. Ibrahim AA, Abdel Aleem MH, Abdella HM and Helmy A: Study of the role of insulin resistance as a risk factor in HCV related hepatocellular carcinoma. J Egypt Soc Parasitol 45: 107-113, 2015.

12. Huang TS, Shyu YC, Chen HY, Yuan SS, Shih JN and Chen PJ: A systematic review and meta-analysis of adjuvant interferon therapy after curative treatment for patients with viral hepatitis-related hepatocellular carcinoma. J Viral Hepat 20: 729-743, 2013.

13. Park YJ, Kim EK, Bae JY, Moon S and Kim J: Human telomerase reverse transcriptase (hTERT) promotes cancer invasion by modulating cathepsin D via early growth response (EGR)-1. Cancer Lett 370: 222-231, 2016.

14. Abdul-Ghani R, Ohana P, Matouk I, Ayesh S, Ayesh B, Laster M, Bibi O, Giladi H, Molnar-Kimber K, Sughayer MA, et al: Use of transcriptional regulatory sequences of telomerase (hTER and hTERT) for selective killing of cancer cells. Mol Ther 2: 539-544, 2000.

15. Stehling O, Mascarenhas J, Vashisht AA, Sheftel AD, Niggemeyer B, Rösser R, Pierik AJ, Wohlschlegel JA and Lill R: Human CIA2A-FAM96A and CIA2B-FAM96B integrate iron homeostasis and maturation of different subsets of cytosolic-nuclear iron-sulfur proteins. Cell Metab 18: 187-198, 2013.

16. Mas C, Chen KE, Brereton IM, Martin JL and Hill JM: Backbone resonance assignments of the monomeric DUF59 domain of human Fam96a. Biomol NMR Assign 7: 117-120, 2013.
17. Chen KE, Richards AA, Ariffin JK, Ross IL, Sweet MJ, Kellie S, Kobe B and Martin JL: The mammalian DUF59 protein Fam96a forms two distinct types of domain-swapped dimer. Acta Crystallogr D Biol Crystallogr 68: 637-648, 2012.

18. Ouyang B, Wang L, Wan S, Luo Y, Lin J and Xia B: Solution structure of monomeric human FAM96A. J Biomol NMR 56: 387-392, 2013.

19. Hawkins P, Morton DB, Burman O, Dennison N, Honess P, Jennings M, Lane S, Middleton V, Roughan JV, Wells S, Westwood K; UK Joint Working Group on Refinement BVAAWF/FRAME/RSPCA/UFAW: A guide to defining and implementing protocols for the welfare assessment of laboratory animals: Eleventh report of the BVAAWF/FRAME/ RSPCA/UFAW Joint Working Group on Refinement. Lab Anim 45: 1-13, 2011.

20. Morotomi N, Fukuda K, Nakano M, Ichihara S, Oono T, Yamazaki T, Kobayashi N, Suzuki T, Tanaka Y and Taniguchi H: Evaluation of intestinal microbiotas of healthy Japanese adults and effect of antibiotics using the 16S ribosomal RNA gene based clone library method. Biol Pharm Bull 34: 1011-1020, 2011.

21. Liang X, Zhang H, Zhang E, Wei J, Li W, Wang B, Dong S and Zhu J: Identification of the pXO1 plasmid in attenuated Bacillus anthracis vaccine strains. Virulence 7: 578-586, 2016.

22. Greaves MF and Brown G: Purification of human $\mathrm{T}$ and B lymphocytes. J Immunol 112: 420-423, 1974.

23. Zamarin D, Vigil A, Kelly K, Garcia-Sastre A and Fong Y: Genetically engineered Newcastle disease virus for malignant melanoma therapy. Gene Ther 16: 796-804, 2009.

24. Livak KJ and Schmittgen TD: Analysis of relative gene expression data using real-time quantitative PCR and the 2(-Delta Delta C(T)) method. Methods 25: 402-408, 2001.

25. Xiong YQ, Sun HC, Zhang W, Zhu XD, Zhuang PY, Zhang JB, Wang L, Wu WZ, Qin LX and Tang ZY: Human hepatocellular carcinoma tumor-derived endothelial cells manifest increased angiogenesis capability and drug resistance compared with normal endothelial cells. Clin Cancer Res 15: 4838-4846, 2009.

26. Hons JM: New insights into the immunomodulatory effects of exercise and potential Impact on tumorigenesis. Oncology (Williston Park) 29: 921-922, 2015.

27. Aldinucci D, Celegato M and Casagrande N: Microenvironmental interactions in classical Hodgkin lymphoma and their role in promoting tumor growth, immune escape and drug resistance. Cancer Lett 380: 243-252, 2016.

28. Webb TE and Galli A: Hepatocellular carcinoma cells that develop resistance to the telomerase-activated prodrug ACV-TP-T may undergo spontaneous apoptosis. Med Hypotheses 85: 383, 2015.

29. Mundt HM, Stremmel W, Melino G, Krammer PH, Schilling T and Müller M: Dominant negative (DeltaN) p63alpha induces drug resistance in hepatocellular carcinoma by interference with apoptosis signaling pathways. Biochem Biophys Res Commun 396: 335-341, 2010.

30. Jablonski EM, Mattocks MA, Sokolov E, Koniaris LG, Hughes FM Jr, Fausto N, Pierce RH and McKillop IH: Decreased aquaporin expression leads to increased resistance to apoptosis in hepatocellular carcinoma. Cancer Lett 250: 36-46, 2007.

31. Mizuno H, Honda M, Shirasaki T, Yamashita T, Mizukoshi E and Kaneko S: Heterogeneous nuclear ribonucleoprotein A2/B1 in association with hTERT is a potential biomarker for hepatocellular carcinoma. Liver Int 32: 1146-1155, 2012.

32. Masutomi K, Kaneko S, Yasukawa M, Arai K, Murakami S and Kobayashi K: Identification of serum anti-human telomerase reverse transcriptase (hTERT) auto-antibodies during progression to hepatocellular carcinoma. Oncogene 21: 5946-5950, 2002.

33. Kim YH, Kim KT, Lee SJ, Hong SH, Moon JY, Yoon EK, Kim S, Kim EO, Kang SH, Kim SK, et al: Image-aided suicide gene therapy utilizing multifunctional hTERT-targeting adenovirus for clinical translation in hepatocellular carcinoma. Theranostics 6 : 357-368, 2016.

34. Schwamb B, Pick R, Fernández SB, Völp K, Heering J, Dötsch V, Bösser S, Jung J, Beinoraviciute-Kellner R, Wesely J, et al: FAM96A is a novel pro-apoptotic tumor suppressor in gastrointestinal stromal tumors. Int J Cancer 137: 1318-1329, 2015.

35. Sacco PC, Maione P,Rossi A, Bareschino MA, Schettino C, Guida C, Elmo M, Ambrosio R, Barbato V, Zeppa R, et al: Combination of radiotherapy and targeted therapies in the treatment of locally advanced non-small cell lung cancer. Target Oncol 6: 171-180, 2011.

36. Batist G, Wu JH, Spatz A, Miller WH Jr, Cocolakis E, Rousseau C, Diaz Z, Ferrario C and Basik M: Resistance to cancer treatment: The role of somatic genetic events and the challenges for targeted therapies. Front Pharmacol 2: 59, 2011. 
37. Aggarwal R and Ryan CJ: Castration-resistant prostate cancer: Targeted therapies and individualized treatment. Oncologist 16: 264-275, 2011

38. Rivera F, Lopez-Tarruella S, Vega-Villegas ME and Salcedo M: Treatment of advanced pancreatic cancer: From gemcitabine single agent to combinations and targeted therapy. Cancer Treat Rev 35: 335-339, 2009.

39. Bunn PA Jr and Kelly K: Combinations of three chemotherapeutic agents and two chemotherapeutic agents plus a targeted biologic agent in the treatment of advanced non small-cell lung cancer. Clin Lung Cancer 2 (Suppl 1): S23-S28, 2000.

40. Cabrespine A, Bay JO, Barthomeuf C, Curé H, Chollet P and Debiton E: In vitro assessment of cytotoxic agent combinations for hormone-refractory prostate cancer treatment. Anticancer Drugs 16: 417-422, 2005.
41. Lee BS, Kim HJ, Hwang JW, Cheong KH, Kim KA, Cha HY, Lee JM and Kim CH: The dual inhibition of Met and EGFR by ME22S, a novel Met/EGFR bispecific monoclonal antibody, suppresses the proliferation and invasion of laryngeal cancer. Ann Surg Oncol 23: 2046-2053, 2016.

42. Taki S, Kamada H, Inoue M, Nagano K, Mukai Y, Higashisaka K, Yoshioka Y, Tsutsumi Y and Tsunoda S: A novel bispecific antibody against human CD3 and ephrin receptor A10 for breast cancer therapy. PLoS One 10: e0144712, 2015.

This work is licensed under a Creative Commons

Attribution-NonCommercial-NoDerivatives 4.0 International (CC BY-NC-ND 4.0) License. 